\section{(2) OPEN ACCESS}

\title{
Mortality in a cohort of US firefighters from San Francisco, Chicago and Philadelphia: an update
}

\author{
Lynne Pinkerton (1) , ${ }^{1}$ Stephen I Bertke, ${ }_{1}^{1}$ James Yiin, ${ }^{1}$ Matthew Dahm, ${ }_{1}^{1}$ Travis Kubale, ${ }^{2}$ \\ Thomas Hales, ${ }^{3}$ Mark Purdue, ${ }^{4}$ James J Beaumont, ${ }^{5}$ Robert Daniels (i) ${ }^{6}$
}

\begin{abstract}
- Additional material is published online only. To view please visit the journal online (http://dx.doi.org/10.1136/ oemed-2019-105962).
\end{abstract}

${ }^{1}$ Division of Surveillance, Hazard Evaluations, and Field Studies, National Institute for Occupational Safety and Health, Cincinnati, Ohio, USA ${ }^{2}$ World Trade Center Health Program, National Institute for Occupational Safety and Health (NIOSH), Washington, District of Columbia, USA

${ }^{3}$ Division of Safety Research, National Institute for Occupational Safety and Health (NIOSH), Denver, Colorado, USA ${ }^{4}$ Division of Cancer Epidemiology and Genetics, National Cancer Institute, Rockville, Maryland, USA ${ }^{5}$ Department of Public Health Sciences, University of California Davis, Davis, California, USA ${ }^{6}$ Education and Information Division, National Institute for Occupational Safety and Health (NIOSH), Cincinnati, Ohio, USA

\section{Correspondence to} Dr James Yiin, Division of Surveillance, Hazard Evaluations, and Field Studies, National Institute for Occupational Safety and Health, Cincinnati, $\mathrm{OH}$ 45226, USA; jyiin@cdc.gov

Received 16 May 2019 Revised 13 November 2019 Accepted 8 December 2019 Published Online First 2 January 2020

\section{Check for updates}

(C) Author(s) (or their employer(s)) 2020. Re-use permitted under CC BY-NC. No commercial re-use. See rights and permissions. Published by BMJ.

To cite: Pinkerton $\mathrm{L}$ Bertke SJ, Yiin J, et al. Occup Environ Med 2020;77:84-93.

\section{ABSTRACT}

Objectives To update the mortality experience of a previously studied cohort of 29992 US urban career firefighters compared with the US general population and examine exposure-response relationships within the cohort.

Methods Vital status was updated through 2016 adding 7 years of follow-up. Cohort mortality compared with the US population was evaluated via life table analyses. Full risk-sets, matched on attained age, race, birthdate and fire department were created and analysed using the Cox proportional hazards regression to examine exposure-response associations between select mortality outcomes and exposure surrogates (exposeddays, fire-runs and fire-hours). Models were adjusted for a potential bias from healthy worker survivor effects by including a categorical variable for employment duration. Results Compared with the US population, mortality from all cancers, mesothelioma, non-Hodgkin's lymphoma (NHL) and cancers of the oesophagus, intestine, rectum, lung and kidney were modestly elevated. Positive exposure-response relationships were observed for deaths from lung cancer, leukaemia and chronic obstructive pulmonary disease (COPD).

Conclusions This update confirms previous findings of excess mortality from all cancers and several sitespecific cancers as well as positive exposure-response relations for lung cancer and leukaemia. New findings include excess NHL mortality compared with the general population and a positive exposure-response relationship for COPD. However, there was no evidence of an association between any quantitative exposure measure and NHL.

\section{INTRODUCTION}

Considerable concern exists about cancer risk among firefighters. Firefighters are potentially exposed to a number of known and suspected carcinogens, including polycyclic aromatic hydrocarbons, polychlorinated biphenyls, formaldehyde, benzene, 1,3-butadiene, asbestos, diesel exhaust and circadian disruption from shift work. ${ }^{1}$ In 2007, an International Agency for Research on Cancer (IARC) working group reported elevated summary relative risk estimates for testicular cancer, prostate cancer and non-Hodgkin's lymphoma (NHL) in a meta-analysis of cancer in firefighters and concluded, based on limited evidence, that occupational exposure as a firefighter is possibly carcinogenic to humans (ie, categorised as Group 2B). The literature includes several studies published

\section{Key messages}

What is already known about this subject?

- We previously reported excess respiratory, digestive and urinary cancers, and mesothelioma, in a cohort of US career firefighters compared with the general population. We also found evidence of positive exposure-response associations for lung cancer and leukaemia risk in regression models using proxies for firefighter exposure.

What are the new findings?

- After extending observation for 7 years, we found previously unreported excess nonHodgkin's lymphoma mortality and increasing chronic obstructive pulmonary disease mortality with the amount of time spent at fires.

\section{How might this impact on policy or clinical practice in the foreseeable future? \\ - The study findings support current efforts to lower disease risks in firefighters, including research on effective methods for exposure reduction.}

since the IARC monograph. ${ }^{2-16}$ Nevertheless, findings still differ among specific cancer sites; perhaps from heterogeneity in exposures, work practices, personal protective equipment use or simply from chance alone. ${ }^{17}$

We previously conducted a study of cancer incidence and mortality among a large cohort of US career firefighters from the San Francisco, Chicago and Philadelphia fire departments. ${ }^{16}$ These firefighters had a $9 \%$ increase in cancer incidence and a $14 \%$ increase in cancer mortality compared with the US general population with elevations observed for respiratory, digestive and urinary cancers as well as mesothelioma. In internal analyses, lung cancer incidence and mortality were weakly associated with the amount of time spent at fires and leukaemia mortality was weakly associated with the number of fire-runs. ${ }^{5}$ Negative exposure-response relations were observed for some outcomes, suggesting a healthy worker survivor effect (HWSE). ${ }^{18}$

In the current study, we updated the mortality experience through 2016, adding 7years of follow-up. From the literature, outcomes of interest were mortality from all causes; all cancers; leukaemia; NHL; multiple myeloma; 
mesothelioma; cancers of the oesophagus, stomach, colon, rectum, kidney, bladder, prostate, testes, brain, lung and skin; chronic obstructive pulmonary disease (COPD) and ischaemic heart disease (IHD). We included cerebrovascular disease, and cirrhosis (along with COPD and IHD) to examine the potential effects of lifestyle-related risk factors. Finally, we examined exposure-response relationships using methods to adjust for the HWSE.

\section{METHODS}

\section{Cohort description}

Details of the study population are described elsewhere. ${ }^{16}$ Briefly, the full study cohort, hereafter referred to as the 'full cohort', includes 29992 career firefighters employed by the fire departments of San Francisco (SFFD), Chicago (CFD) or Philadelphia (PFD) for at least 1 day between the years 1950 and 2009 deleting one duplicate record. Firefighters of unknown race $(n=753)$ were assumed white because $83 \%$ of firefighters of known race were white and $71 \%$ of firefighters of unknown race were hired during earlier periods of lower minority hiring (before 1970). Among non-white firefighters, $<8 \%$ were hired before 1970 . Consistent with the previous study, ${ }^{5}$ the cohort used in the exposure-response analysis, hereafter referred to as the 'restricted cohort', was limited to male firefighters of known race hired in 1950 or later for at least 1 year. Of the 19309 male firefighters in the previous exposureresponse analysis, 22 were excluded because race was missing $(n=10)$ or employment duration was less than 1 year $(n=12)$.

\section{Exposure assessment}

Detailed information on the retrospective exposure assessment is available elsewhere. ${ }^{19}$ Briefly, researchers calculated three separate exposure surrogates (exposed-days, fire-runs and fire-hours) by linking detailed work histories through 2009 with job exposure matrices based on job, location and fire-fighting apparatus assignments as described previously. Data were available to calculate the number of exposed-days (ie, days worked in a job or location with potential exposure) for all firefighters, the number of fire-runs for CFD and PFD firefighters and the number of fire-hours (ie, the time spent at fires) for CFD firefighters.

\section{Follow-up}

Vital status through 2009 was described previously. ${ }^{16}$ Vital status was updated through 31 December, 2016, by linkages with the National Death Index-Plus (NDI-Plus), the Social Security Administration Death Master File and the Internal Revenue Service. Cohort members known to be alive in 1979 (when NDI began) or later with a social security number not known to be invalid and not identified as deceased were assumed alive as of 31 December, 2016. The sensitivity of the NDI is over $95 \%$ when social security numbers are available. ${ }^{20}$ Causes of death for newly identified deaths were obtained from NDI-Plus.

\section{Analysis}

\section{Life table analyses}

External comparisons were made by life table using NIOSH LTAS. NET (National Institute for Occupational Safety and Health Life Table Analysis System). ${ }^{21}$ International Classification of Diseases codes for the underlying causes of death were mapped to 92 cause of death categories as described on the NIOSH LTAS.NET website (https://www.cdc.gov/niosh/ltas/pdf/Rate-Info-Table-3. pdf). For each cohort member, person-years-at-risk (PYAR) began on 1 January, 1950, or the date of cohort inclusion, whichever was later, and ended on the earliest of the date of death, the date last observed, or the study end date (31 December, 2016). PYAR stratified by gender, race (white, other) and 5 year intervals of age and calendar time were multiplied by the appropriate US general population cause-specific mortality rates to calculate the expected number deaths for each stratum. The expected numbers were summed across strata to obtain cause-specific and total expected number of deaths. The standardised mortality ratio (SMR) was calculated as the ratio of the observed to expected number of deaths. Ninety-five per cent CIs were computed for the SMRs assuming a Poisson distribution for observed deaths. SMRs were stratified by fire department for all cause of death categories and by gender, race and age-at-risk (17 to 64, 65 + years) for outcomes of interest. Heterogeneity by fire department and age-at-risk for outcomes of interest was evaluated using the method of Breslow and Day. ${ }^{22}$

Sensitivity analyses were conducted using state mortality rates (California (CA), Illinois (IL) and Pennsylvania (PA) for SFFD, CFD and PFD firefighters, respectively) as referent. The rate files did not include categories for colon cancer, testicular cancer or skin melanoma specifically; however, most intestinal cancers were colon cancers, few deaths from male genital cancers other than prostate cancer were observed and mortality from nonmelanoma skin cancer is low.

\section{Exposure-response modelling}

Exposure-response associations within this restricted cohort were examined by Cox proportional hazards regression using the SAS PHREG procedure. ${ }^{23}$ Analyses included two separate approaches to exposure-response: (1) a standard approach assuming the response is linear in the log of dose, and (2) an exposure-response function specified by restricted cubic splines (RCS) with knots evenly spaced across the exposure distribution. Risk-sets comprised those persons at risk as of the attained age of the case. Risk-sets were also matched on race, birthdate (within 5 years) and department. Restricted cohort members were followed from the completion of the 1 year eligibility period until the earliest of the date of death, the date last observed or 31 December, 2016. Cumulative exposure was lagged 5 years for leukaemia and 10 years for other outcomes. In leukaemia analyses, person-time for 7690 firefighters employed at the end of the exposure assessment (31 December, 2009) was truncated at 31 December, 2014, to avoid exposure misclassification.

There was little evidence of an association between work status and prior exposure for fire-runs and fire-hours; therefore, the HWSE was addressed by including a term for employment duration $(<10,10$ to $<20,20$ to $<30,30+$ years). Models without adjustment for employment duration were also evaluated. HR were estimated from the maximum partial likelihood, significance tests were based on the partial likelihood ratio test (LRT) and two-sided 95\% CIs were based on the profile likelihood. HRs are reported at the $75^{\text {th }}$ centile of exposure compared with the $25^{\text {th }}$ centile of exposure, rounded to the nearest 100 units. ${ }^{5}$ For positive associations, potential non-linearity in the $\log (\mathrm{HR})$ with dose was assessed by the LRT comparing the RCS and loglinear models and visually examining the models when the LRT $\mathrm{p}$ value was $<0.10$.

Time since exposure (lag to $<20,20$ to $<30,30+$ years), age at exposure $(<40,40+$ years $)$ and exposure period $(<1970$, $1970+)$ were examined in employment duration-adjusted loglinear models with cumulative exposure divided into time windows using the same cut-points for age at exposure and exposure period as in the previous analysis. Effect modification was evaluated by the LRT comparing the model with one 
exposure variable to models with time windows. All modelling was restricted to analyses including 30 or more observed cases.

\section{RESULTS}

Table 1 shows demographic characteristics of the full and restricted cohorts. Firefighters in the full cohort contributed 1029858 PYAR. Most (97\%) members of the full cohort were male; 47\% were deceased. In contrast, $29 \%$ of the restricted cohort was deceased. Most cohort members were white $81 \%$ and $78 \%$ for the full and restricted cohorts, respectively). The mean employment duration for both cohorts was 20 years or more.

\section{Mortality among the full cohort}

Table 2 shows SMRs for outcomes of interest in the full cohort with the US general population referent. Mortality from all causes was slightly less than expected $(\mathrm{SMR}=0.97 ; 95 \% \mathrm{CI} 0.95$ to 0.98$)$. Mortality was elevated for all cancers $(\mathrm{SMR}=1.12$; $95 \%$ CI 1.08 to 1.16$)$, mesothelioma ( $\mathrm{SMR}=1.86$; 95\% CI 1.10 to 2.94$)$, NHL (SMR $=1.21 ; 95 \% \mathrm{CI} 1.03$ to 1.42$)$ and cancers of the oesophagus $(\mathrm{SMR}=1.31 ; 95 \% \mathrm{CI} 1.10$ to 1.55$)$, intestine $(\mathrm{SMR}=1.27 ; 95 \% \mathrm{CI} 1.14$ to 1.40$)$, rectum $(\mathrm{SMR}=1.32$; $95 \% \mathrm{CI} 1.07$ to 1.61$)$, lung $(\mathrm{SMR}=1.08 ; 95 \% \mathrm{CI} 1.02$ to 1.15$)$ and kidney $(\mathrm{SMR}=1.22 ; 95 \% \mathrm{CI} 1.00$ to 1.47$)$. Among nonmalignant outcomes of interest, mortality was elevated for cirrhosis and other chronic liver disease $(\mathrm{SMR}=1.16 ; 95 \% \mathrm{CI}$ 1.03 to 1.29 ), lower than expected for cerebrovascular disease $(\mathrm{SMR}=0.90 ; 95 \% \mathrm{CI} 0.83$ to 0.97$)$ and $\mathrm{COPD}(\mathrm{SMR}=0.78$; $95 \% \mathrm{CI} 0.71$ to 0.85$)$, and similar to expected for IHD $(\mathrm{SMR}=0.98 ; 95 \% \mathrm{CI} 0.95$ to 1.01$)$.

Mortality was significantly elevated for cancers of the buccal cavity and pharynx $(\mathrm{SMR}=1.35 ; 95 \% \mathrm{CI} 1.11$ to 1.63$)$; biliary, liver and gallbladder $(\mathrm{SMR}=1.36 ; 95 \% \mathrm{CI} 1.15$ to 1.60$)$ and peritoneum and other and unspecified digestive cancers $(\mathrm{SMR}=1.64 ; 95 \% \mathrm{CI} 1.02$ to 2.51$)$. Mortality from diabetes mellitus $(\mathrm{SMR}=0.73 ; 95 \% \mathrm{CI} 0.64$ to 0.83$)$, alcoholism $(\mathrm{SMR}=0.64 ; 95 \% \mathrm{CI} 0.45$ to 0.87$)$, nervous system disorders $(\mathrm{SMR}=0.89 ; 95 \% \mathrm{CI} 0.80$ to 1.00$)$ and non-malignant respiratory diseases $(\mathrm{SMR}=0.81 ; 95 \% \mathrm{CI} 0.76$ to 0.86$)$ remained lower than expected (online supplementary table 1 ).

Heterogeneity by fire department was observed for mortality from all causes, all cancers, lung cancer, IHD and COPD (table 2). In general, mortality from these causes, compared with the US general population, was lower among San Francisco firefighters than Chicago and Philadelphia firefighters. Excluding firefighters employed less than 1 year $(n=1208)$ did not appreciably change SMRs.

\section{Mortality among women and firefighters of other races}

Among women, mortality from all causes $(\mathrm{SMR}=0.92 ; 95 \% \mathrm{CI}$ 0.67 to $1.23 ; \mathrm{n}=45)$ and all cancers $(\mathrm{SMR}=1.01 ; 95 \% \mathrm{CI} 0.56$ to $1.67 ; n=15)$ remained near expectation. The remaining outcomes of interest had five or fewer deaths. Mortality from bladder cancer remained significantly elevated $(\mathrm{SMR}=17.6$; $95 \%$ CI 2.13 to 63.6). Mortality from NHL (SMR=2.71; $95 \% \mathrm{CI} 0.07$ to 15.1$)$, multiple myeloma $(\mathrm{SMR}=5.27 ; 95 \% \mathrm{CI}$ 0.13 to 29.4$)$ and cancers of the lung $(\mathrm{SMR}=1.37 ; 95 \% \mathrm{CI} 0.37$ to 3.51$)$ and breast $(\mathrm{SMR}=1.41 ; 95 \% \mathrm{CI} 0.46$ to 3.30$)$ was elevated, but not significantly. The SMR for IHD was $1.11(95 \%$ CI 0.36 to 2.60 ).

There were no significant elevations in outcomes of interest among non-white firefighters (online supplementary table 2). Mortality from all causes $(\mathrm{SMR}=0.68 ; 95 \% \mathrm{CI} 0.63$ to 0.74$)$, all cancers $(\mathrm{SMR}=0.79 ; 95 \% \mathrm{CI} 0.68$ to 0.93$)$ and lung cancer
$(\mathrm{SMR}=0.57 ; 95 \% \mathrm{CI} 0.39$ to 0.80$)$ remained significantly lower than expected.

\section{Other external comparisons}

Mortality from all causes, all cancers, NHL and cancers of the stomach, intestine and lung was significantly elevated among firefighters 65 years of age and older, but not among younger firefighters (online supplementary table 3). Mortality from IHD and cerebrovascular disease was significantly less than expected among firefighters less than 65 years of age, but not among older firefighters.

SMRs based on state reference rates (online supplementary table 4) were slightly less than estimates obtained using US rates (table 2). Excess kidney cancer mortality was no longer marginally significant. Excess mortality from cancers of the rectum, lung and mesothelioma was no longer statistically significant; however, there was essentially no difference in heterogeneity by fire department comparing USA and state rates (table 2, online supplementary table 4).

\section{Exposure-response}

Results herein stem from loglinear models with adjustment for the HWSE unless stated otherwise. A positive association of borderline statistical significance was observed for mortality from all cancers with exposed-days, but not with fire-runs or fire-hours (table 3). The exposure-response association between lung cancer mortality and each exposure metric was significant, with evidence of monotonicity (table 3, online supplementary figure 1). There was a significant positive association between leukaemia mortality and exposed-days, but not fire-runs or firehours. However, visual inspection revealed that the loglinear model for fire-runs did not fit the data well based on comparison to the exposure-response using a RCS model (online supplementary figure 1). The model indicated increasing leukaemia mortality risk at low exposures followed by attenuated risk at higher exposure. Similar exposure-response patterns were evident in plots of COPD and ischaemic heart disease mortality and fire-hours; however, only the adjusted RCS model for COPD mortality achieved statistical significance. The HR for cirrhosis and other chronic liver disease was significant and positive in adjusted models for exposed-days. Statistically significant, negative associations were observed for rectal cancer and IHD in models without adjustment for employment duration.

Online supplementary tables 5-6 show associations of outcomes of interest with fire-runs by time since exposure, age at exposure and exposure period. A positive association of oesophageal cancer $(\mathrm{HR}=2.00 ; 95 \%$ CI 1.01 to 3.69$)$ and IHD $(\mathrm{HR}=1.20 ; 95 \% \mathrm{CI} 0.99$ to 1.44$)$ with fire-runs before, but not after, 1970 was observed.

\section{DISCUSSION}

Consistent with the previous study of this cohort, there was increased mortality from all cancers and from several site-specific cancers of interest. Compared with the US general population, mortality from mesothelioma, NHL and cancers of the oesophagus, intestine, rectum, lung and kidney was increased. Mortality from peritoneal, other and unspecified digestive cancers (Minor ID 13, online supplementary table 1), a category that includes peritoneal mesotheliomas, was also elevated. A new finding was an increase in NHL mortality, consistent with previous metaanalyses of cancer among firefighters. ${ }^{1} 15$

Excess lung cancer mortality appeared restricted to older firefighters. Lung cancer risk among firefighters was not elevated in 


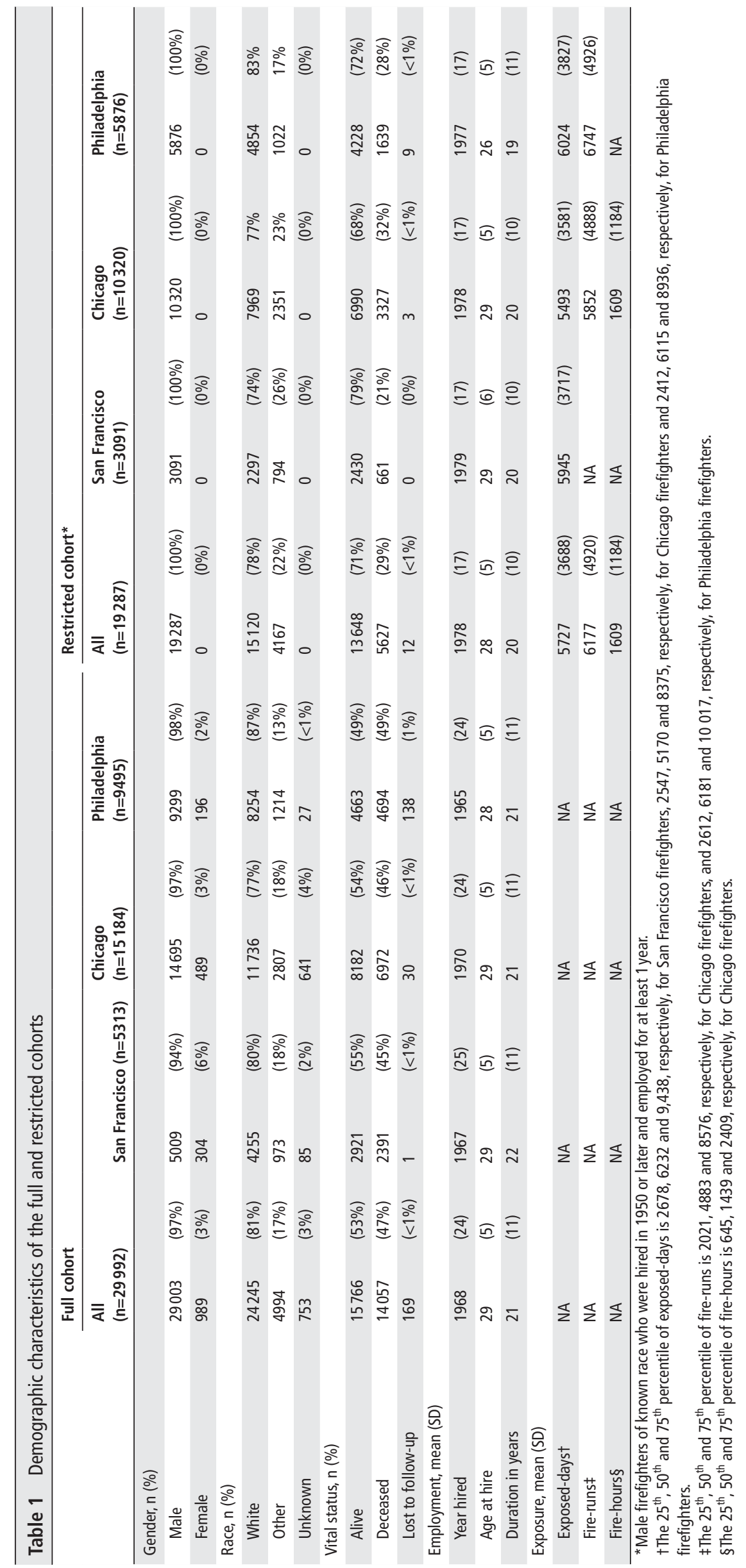




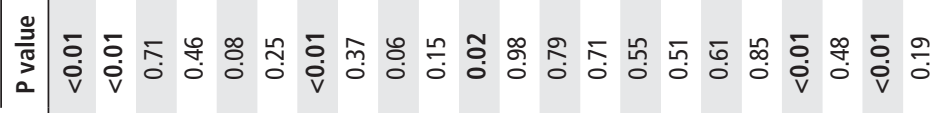

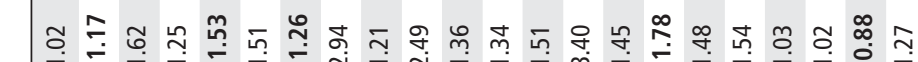

ব

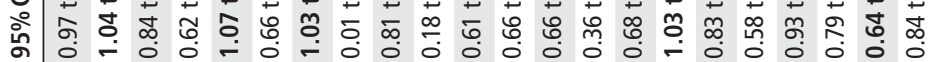

产旁

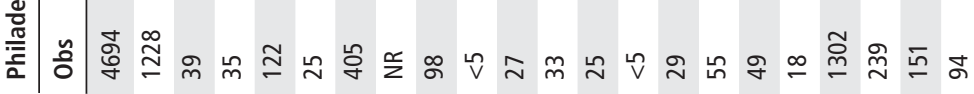

एᄂ

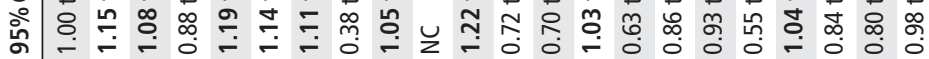

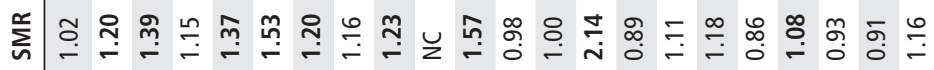

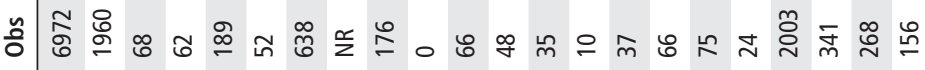

๓

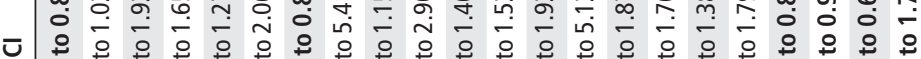

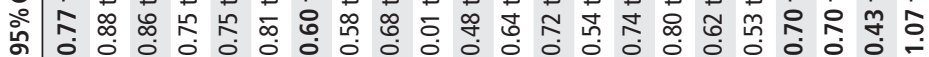

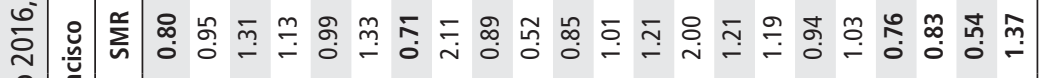

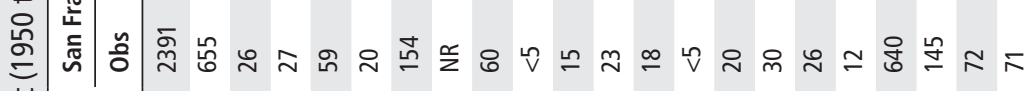

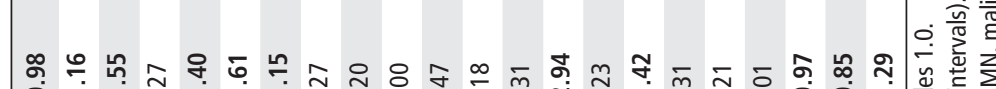

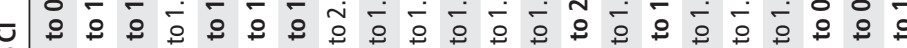

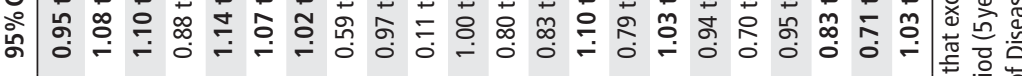

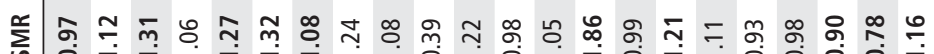

离

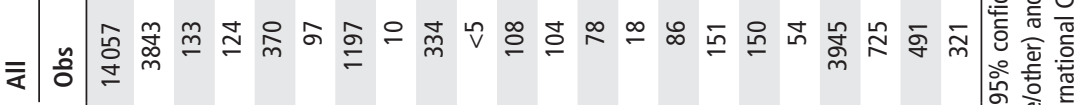




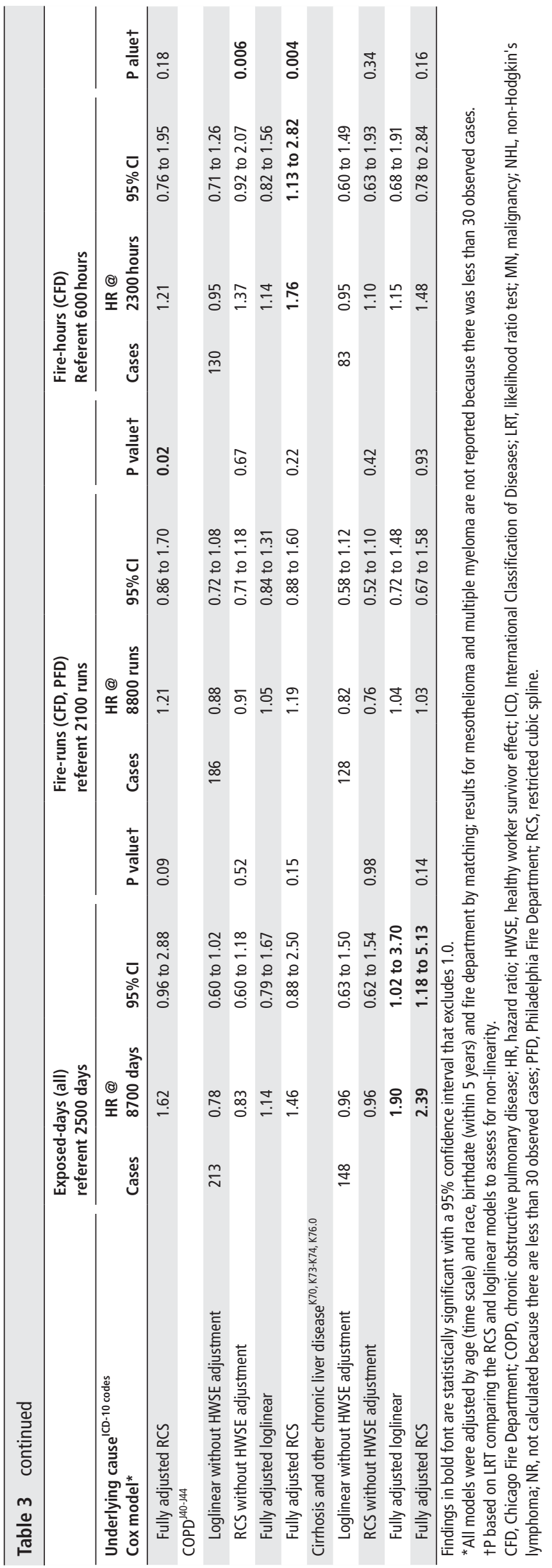

most other studies or meta-analyses, ${ }^{15} 2425$ but excess lung cancer incidence, especially adenocarcinoma, was evident among older, but not younger, Nordic firefighters. ${ }^{13}$ Exposure-response analyses revealed statistically significant positive associations of lung cancer regardless of the exposure surrogate. In contrast, the previous study reported an association of lung cancer with cumulative fire-hours only without HWSE adjustment. ${ }^{5}$ Negative confounding by employment duration was evident in all models of lung cancer and strongest in the model using exposed-days.

As in the previous study, a modest positive association of leukaemia mortality with cumulative fire-runs was observed. Leukaemia mortality was mildly elevated $(S M R=1.11)$, but not statistically significant. Leukaemia risk was not significantly elevated in previous meta-analyses or in recent large cohort studies. $^{2367131525}$

There was little evidence an exposure-response in other cancer outcomes, although several had SMRs indicating modest excess risk. In addition to low statistical power to observe weak effects, possible explanations for lacking exposure-response evidence when SMRs are elevated include: exposure misclassification from crudely defined indirect exposure measures, selection bias from differences between the cohort and general population and incomplete confounding control (eg, HWSEs).

Some positive findings were restricted to older workers or for exposures prior to 1970. Stomach cancer was significantly elevated among older, but not younger, firefighters. Oesophageal cancer, which was elevated in the full cohort, was positively associated with fire-runs prior to 1970 only. Stomach cancer was elevated in an early meta-analysis, ${ }^{25}$ but not in a later metaanalysis or recent large cohort studies. ${ }^{2} 671315$ Oesophageal cancer was not elevated in meta-analyses or recent large cohort studies. $^{2367131525}$

Heart and respiratory diseases are also of concern to the fire service. Fire smoke contains many substances that may be toxic to the airways. Substantial inhalational exposure can occur during fire response activities where respiratory protection may not be worn. ${ }^{26}$ Acute airway inflammation has been documented. ${ }^{27}$ However, it remains unclear whether urban career firefighters without exposure to a non-routine disastrous event have an accelerated decline in pulmonary function. ${ }^{28}$ In our study, COPD mortality was significantly associated with cumulative fire-hours, after adjusting for employment duration. The lower than expected COPD mortality based on general population mortality rates is consistent with the healthy worker hire effect and/or a lower smoking prevalence among the cohort.

Sudden cardiac deaths are the most common cause of on-duty deaths among US firefighters, accounting for $48 \%$ of such deaths in $2017 .{ }^{29}$ A higher risk of these deaths has been observed during fire suppression and other high-risk duties compared with lowrisk duties. ${ }^{3031}$ This risk may be related to cardiovascular strain from strenuous physical exertion, heat stress and dehydration, stress-induced activation of the sympathetic nervous system and exposure to fire smoke. ${ }^{32}$ Firefighters may also have an increased cardiovascular disease risk after employment ends. In our study, the risk of IHD mortality was at expectation based on general population mortality rates. However, IHD mortality is usually less than expected in occupational cohorts due to the healthy worker hire effect. In analyses adjusting for employment duration, IHD mortality increased with the cumulative amount of time spent at a fire, although not significantly. These findings are suggestive of an increased IHD mortality risk associated with work at fires. Similarly, the risk of angina pectoris, acute myocardial infarction and chronic IHD was elevated among Danish firefighters compared with other workers, but not during active 
employment as a firefighter. ${ }^{33}$ The risk of angina pectoris and acute myocardial infarction was also elevated among Korean firefighters compared with other workers. ${ }^{34}$ In addition, IHD mortality was associated with the number of incidents among volunteer Australian firefighters. However, these volunteer firefighters may have had different exposures than structural firefighters because they respond to more bushfires and tended to not wear respiratory protection. ${ }^{6}$

Loglinear models of leukaemia with fire-runs and COPD and IHD with fire-hours did not fit the data well due to attenuation of risk at high exposures. Attenuation of the exposure-response at high exposures is common in occupational studies and may result from the HWSE, depletion of the susceptible population, exposure misclassification, other risk factors that vary by exposure and biological saturation. ${ }^{35}$ Despite adjustment for employment duration, residual bias from the HWSE is possible in this update.

Nonetheless, a strength of this update is the assessment of exposure-response relations accounting for the HWSE. Negative confounding by employment duration obscured positive exposure-response relations for several outcomes in unadjusted models. The appropriate method to account for the HWSE depends on the association between: (1) prior exposure and employment status, (2) employment status and subsequent exposure and (3) employment status and survival. ${ }^{36}$ In this update, cumulative fire-runs and fire-hours were not associated with leaving employment (data not shown); therefore, standard regression analyses adjusting for employment duration appeared appropriate for controlling HWSE. Other strengths of this study include the large cohort size and the long follow-up time.

Limitations include relatively few women and non-white firefighters under observation and the lack of information on potential confounders such as smoking and alcohol use. In addition, mortality is not a sensitive outcome measure for cancers with relatively good survival rates such as cancers of the prostate, testes and breast.

If a bias from smoking exists, the direction is unclear. Changes in the fire service culture as well as smoking-related policies and regulations have led to a substantial decline in smoking among firefighters, ${ }^{37}$ and recent data suggest firefighters are less likely to smoke than the general population. ${ }^{38}$ However, other data indicate that firefighters may have been more likely to smoke than the general population in earlier years. ${ }^{39}$ In addition, mortality from most smoking-related cancers was elevated in the cohort compared with the general population, but mortality from COPD, which is strongly associated with smoking, ${ }^{40}$ was not elevated. As in the original study, the inconsistencies in the findings for smoking-related outcomes suggest that a strong bias from smoking is unlikely. Nonetheless, SMRs for smokingrelated outcomes (eg, lung cancer, COPD) by department suggest that there may be differences by department in smoking, with San Francisco firefighters smoking less. However, the heterogeneity in SMRs by department could also be due to differences in exposure or work practices. Research evaluating differences that explain this heterogeneity might provide insight into effective methods for exposure reduction. Inconsistencies were also observed for alcohol-related outcomes. Excess mortality was observed for cirrhosis and alcohol-related cancers, but mortality from alcoholism remained significantly less than expected.

\section{CONCLUSION}

In conclusion, this update confirms previous findings of excess mortality from all cancers and several site-specific cancers as well as positive exposure-response relations for lung cancer and leukaemia. New findings include excess NHL mortality and an increase in COPD mortality with increasing fire-hours. A suggestive association of IHD mortality with cumulative fire-hours was also observed.

Acknowledgements This study was made possible through the continued cooperation of the fire departments of Chicago, Philadelphia and San Francisco. We acknowledge and thank the National Death Index for providing death data for this update. We also thank current and former NIOSH staff and contractors for their contributions to the cleaning and management of the data.

Contributors LP participated in the collection of the follow-up data and wrote the first draft of the manuscript. SJB and JY conducted the analysis. All authors participated in the interpretation and presentation of results and have approved the final manuscript.

Funding The study was funded, in part, by an interagency agreement with the United States Fire Administration. The research was also supported, in part, by the intramural research programs at the National Cancer Institute and the National Institute for Occupational Safety and Health.

Disclaimer The findings and conclusions in this report are those of the authors and do not necessarily represent the views of the National Institute for Occupational Safety and Health.

Competing interests None declared.

Patient consent for publication Not required.

Ethics approval The study received approvals from the Institutional Review Boards of the National Institute for Occupational Safety and Health and the National Cancer Institute. Informed consent was waived for this records-based study.

Provenance and peer review Not commissioned; externally peer reviewed. Data availability statement The data are protected by a 308(d) assurance of confidentiality that stipulates the data can only be accessed through a National Center for Health Statistics (NCHS) Research Data Center (RDC). Data will be made available to an NCHS RDC upon approval of a reasonable proposal for the data.

Open access This is an open access article distributed in accordance with the Creative Commons Attribution Non Commercial (CC BY-NC 4.0) license, which permits others to distribute, remix, adapt, build upon this work non-commercially, and license their derivative works on different terms, provided the original work is properly cited, appropriate credit is given, any changes made indicated, and the use is non-commercial. See: http://creativecommons.org/licenses/by-nc/4.0/.

\section{ORCID iDs}

Lynne Pinkerton http://orcid.org/0000-0002-8669-487X

Robert Daniels http://orcid.org/0000-0002-3915-7991

\section{REFERENCES}

1 International agency for research on cancer. IARC Working group on the evaluation of carcinogenic risks to humans. painting, firefighting, and shiftwork. IARC Monogr Eval Carcinog Risks Hum 2010;98:9-764.

2 Ahn Y-S, Jeong KS. Mortality due to malignant and non-malignant diseases in Korean professional emergency responders. PLOS One 2015;10:e0120305.

3 Ahn Y-S, Jeong K-S, Kim K-S. Cancer morbidity of professional emergency responders in Korea. Am J Ind Med 2012;55:768-78.

4 Amadeo B, Marchand J-L, Moisan F, et al. French firefighter mortality: analysis over a 30-year period. Am J Ind Med 2015;58:437-43.

5 Daniels RD, Bertke S, Dahm MM, et al. Exposure-response relationships for select cancer and non-cancer health outcomes in a cohort of US firefighters from San Francisco, Chicago and Philadelphia (1950-2009). Occup Environ Med 2015;72:699-706.

6 Glass DC, Del Monaco A, Pircher S, et al. Mortality and cancer incidence among male volunteer Australian firefighters. Occup Environ Med 2017;74:628-38.

7 Glass DC, Pircher S, Del Monaco A, et al. Mortality and cancer incidence in a cohort of male paid Australian firefighters. Occup Environ Med 2016;73:761-71.

8 Harris MA, Kirkham TL, MacLeod JS, et al. Surveillance of cancer risks for firefighters, police, and armed forces among men in a Canadian census cohort. Am J Ind Med 2018;61:815-23

9 Kullberg C, Andersson T, Gustavsson P, et al. Cancer incidence in Stockholm firefighters 1958-2012: an updated cohort study. Int Arch Occup Environ Health 2018;91:285-91.

10 Muegge CM, Zollinger TW, Song Y, et al. Excess mortality among Indiana firefighters, 1985-2013. Am J Ind Med 2018;61:961-7.

11 Petersen KU, Pedersen JE, Bonde JP, et al. Mortality in a cohort of Danish firefighters; 1970-2014. Int Arch Occup Environ Health 2018;91:759-66. 
12 Kirstine Ugelvig Petersen K, Pedersen JE, Bonde JP, et al. Long-Term followup for cancer incidence in a cohort of Danish firefighters. Occup Environ Med 2018;75:263-9.

13 Pukkala E, Martinsen Jl, Weiderpass E, et al. Cancer incidence among firefighters: 45 years of follow-up in five Nordic countries. Occup Environ Med 2014;71:398-404.

14 Tsai RJ, Luckhaupt SE, Schumacher P, et al. Risk of cancer among firefighters in California, 1988-2007. Am J Ind Med 2015;58:715-29.

15 Crawford JO, Winski T, McElvenny D, et al. Firefighters and cancer: the epidemiological evidence, Edinburgh. UK: Institute of Occupational Medicine (IOM), 2017: 1-157.

16 Daniels RD, Kubale TL, Yiin JH, et al. Mortality and cancer incidence in a pooled cohort of US firefighters from San Francisco, Chicago and Philadelphia (1950-2009). Occup Environ Med 2014;71:388-97.

17 Fritschi L, Glass DC. Firefighters and cancer: where are we and where to now? Occup Environ Med 2014;71:525-6.

18 Arrighi HM, Hertz-Picciotto I. The evolving concept of the healthy worker survivor effect. Epidemiology 1994;5:189-96.10.1097/00001648-199403000-00009

19 Dahm MM, Bertke $S$, Allee $S$, et al. Creation of a retrospective job-exposure matrix using surrogate measures of exposure for a cohort of US career firefighters from San Francisco, Chicago and Philadelphia. Occup Environ Med 2015;72:670-7.

20 Cowper DC, Kubal JD, Maynard C, et al. A primer and comparative review of major U.S. mortality databases. Ann Epidemio/ 2002;12:462-8.

21 Schubauer-Berigan MK, Hein MJ, Raudabaugh WM, et al. Update of the NIOSH life table analysis system: a person-years analysis program for the windows computing environment. Am J Ind Med 2011;54:915-24.

22 Breslow NE, Day NE. Statistical methods in cancer research. Volume II--The design and analysis of cohort studies

23 SAS Software, Version 9.4, Copyright (2002-2012). Sas and all other SAS Institute Inc. product or service names are registered trademarks or trademarks of SAS Institute Inc. Cary, NC, USA: SAS Institute Inc.

24 Bigert C, Gustavsson P, Straif K, et al. Lung cancer among firefighters: smokingadjusted risk estimates in a pooled analysis of case-control studies. J Occup Environ Med 2016:58:1137-43.

25 LeMasters GK, Genaidy AM, Succop P, et al. Cancer risk among firefighters: a review and meta-analysis of 32 studies. J Occup Environ Med 2006:48:1189-202.
26 Fent KW, Evans DE, Babik K, et al. Airborne contaminants during controlled residential fires. J Occup Environ Hyg 2018;15:399-412.

27 Greven FE, Krop EJ, Spithoven JJ, et al. Acute respiratory effects in firefighters. Am J Ind Med 2012:55:54-62.

28 Slattery F, Johnston $K_{\text {, Paquet }}$, et al. The long-term rate of change in lung function in urban professional firefighters: a systematic review. BMC Pulm Med 2018;18:149.

29 Fahy RF, LeBlanc PR, Molis JL. Firefighter fatalities in the United States-2017, Quincy. MA: National Fire Protection Association, 2018: 1-33

30 Farioli A, Christophi CA, Quarta CC, et al. Incidence of sudden cardiac death in a young active population. J Am Heart Assoc 2015;4:e001818.

31 Kales SN, Soteriades ES, Christophi CA, et al. Emergency duties and deaths from heart disease among firefighters in the United States. N Engl J Med 2007;356:1207-15.

32 Smith DL, Barr DA, Kales SN. Extreme sacrifice: sudden cardiac death in the US fire service. Extrem Physiol Med 2013;2

33 Pedersen JE, Ugelvig Petersen $\mathrm{K}$, Ebbehøj NE, et al. Incidence of cardiovascular disease in a historical cohort of Danish firefighters. Occup Environ Med 2018;75:337-43.

34 Han M, Park S, Park JH, et al. Do police officers and firefighters have a higher risk of disease than other public officers? A 13-year nationwide cohort study in South Korea. BMJ Open 2018:8:e019987.

35 Stayner L, Steenland K, Dosemeci M, et al. Attenuation of exposure-response curves in occupational cohort studies at high exposure levels. Scand J Work Environ Health 2003:29:317-24.

36 Naimi Al, Cole SR, Hudgens MG, et al. Assessing the component associations of the healthy worker survivor bias: occupational asbestos exposure and lung cancer mortality. Ann Epidemiol 2013;23:334-41.

37 Poston WSC, Haddock CK, Jitnarin N, et al. A national qualitative study of tobacco use among career firefighters and department health personnel. Nicotine Tob Res 2012:14:734-41.

38 Jitnarin N, Poston WSC, Haddock CK, et al. Tobacco use pattern among a nationa firefighter cohort. Nicotine Tob Res 2015;17:66-73.

39 Nelson DE, Emont SL, Brackbill RM, et al. Cigarette smoking prevalence by occupation in the United States. A comparison between 1978 to 1980 and 1987 to 1990. J Occup Med 1994;36:516-25.

40 Jayes L, Haslam PL, Gratziou CG, et al. SmokeHaz: systematic reviews and metaanalyses of the effects of smoking on respiratory health. Chest 2016:150:164-79. 